\title{
O NACIONALISMO BRASILEIRO EM PROSA: ROCHA POMBO E NARRATIVA HISTÓRICA DE NOSSA PÁTRIA
}

\author{
Mariana Rodrigues Tavares
}

Resumo: Este artigo versa a respeito da obra Nossa Pátria - Narração dos factos da Historia do Brasil, atraves da sua evolução com muitas gravuras explicativas do intelectual paranaense José Francisco da Rocha Pombo. Para além disso, o artigo procura apresentar o processo de vulgarização das obras históricas acontecido nas Primeiras décadas da República brasileira, destacando os principais argumentos e características desses livros que tinham por objetivo promover a exaltação da nação brasileira.

Palavras-chave: nacionalismo; vulgarização histórica; intelectuais.

Abstract: This article discusses about the book Nossa Pátria - Narração dos factos da Historia do Brasil of Paraná intellectual José Francisco da Rocha Pombo. Furthermore, the article presents the process of vulgarization of historical works decades happened in the First Republic of Brazil, highlighting key characteristics of these arguments and books that were intended to promote the exaltation of the Brazilian nation.

Keywords: nationalism; historical vulgarization; intellectuals.

Graduanda em História pela Universidade Federal Fluminense e bolsista PIBIC/CNPq. O presente artigo faz parte de um projeto maior de estudos acerca da História Intelectual na Primeira República sob o título de Disputas Intelectuais, Monumentalização e Apropriação da Produção Histórica da Primeira República nos anos 50 e 60, orientado pela professora Giselle Martins Venâncio. E-mail: historia.mari@gmail.com. 


\title{
O NACIONALISMO BRASILEIRO EM PROSA: ROCHA POMBO E NARRATIVA HISTÓRICA DE NOSSA PÁTRIA ${ }^{1}$
}

\author{
Mariana Rodrigues Tavares
}

"Dos diversos instrumentos utilizados pelo homem, o mais espetacular é, sem dúvida, o livro. Os demais são extensões de

seu corpo. O microscópio, o telescópio são extensões de sua

visão; o telefone é extensão de sua voz; em seguida, temos o arado e a espada, extensões de seu braço. O livro, porém, é outra coisa: o livro é extensão da memória e da imaginação." Jorge Luis Borges (2002, p. 13)

“Os livros não matam a fome, não suprimem a miséria, não acabam com as desigualdades e com as injustiças do mundo, mas consolam as almas, e fazem-nas sonhar". Olavo Bilac (apud DIMAS, 2006, p. 187)

Todos os livros, quaisquer que sejam já representam um objeto sagrado $^{2}$. São sagrados por uma série de razões e representam

\footnotetext{
${ }^{1}$ Uma versão do conteúdo deste artigo foi apresentada no XV Encontro Regional de História - Ofício do Historiador: Ensino e Pesquisa por meio do trabalho intitulado "Por entre as páginas do Nacionalismo Histórico brasileiro: Rocha Pombo e a Narrativa Histórica de Nossa Pátria”, ocorrido entre 23 e 27 de julho de 2012.
}

${ }^{2}$ BORGES. Obras completas (Otras Inquisiciones). 
instrumentos mágicos capazes de nos transportar para diversos lugares e épocas, abrir a imaginação de nós leitores, promoverem cultura e etc. Ao inserir a produção de livros ao longo da Primeira República é possível identificar a emergência de um gênero literário referente à produção e circulação de manuais escolares patrióticos de ampla difusão no decorrer desses anos iniciais republicanos, compondo o que se pode denominar por uma pedagogia da nacionalidade ${ }^{3}$. Nesse ínterim repleto de inúmeros autores e obras como Capistrano de Abreu, João Ribeiro, Viriato Corrêa e suas Histórias do Brasil a análise aqui realizada destaca um pequeno livrinho "dedicado às crianças e aos homens simples do povo" intitulado Nossa Pátria - Narração dos factos da Historia do Brasil, atraves da sua evolução com muitas gravuras explicativas ${ }^{4}$ de José Francisco da Rocha Pombo.

Desde o seu lançamento em 1917 pela Cia. Melhoramentos de São Paulo, Nossa Patria, permaneceu no catálogo da editora até a década de 1970. Adotado em diversos estados brasileiros graças à atuação da Editora Melhoramentos e seus agentes em cada estado, o respectivo livro contabilizou a soma de 88 reedições, 452 mil

${ }^{3}$ GOMES, Ângela de Castro. "República, educação e história pátria no Brasil e em Portugal”. In: A República, a História e o IHGB. Belo Horizonte, MG: Argvmentvm, 2009.

${ }^{4}$ ROCHA POMBO, José Francisco da. Nossa Pátria : Narração dos factos da Historia do Brasil, atraves da sua evolução com muitas gravuras explicativas. $34^{\text {a }}$ ed. São Paulo: Companhia Melhoramentos de São Paulo, 1925 [1917]. 
exemplares impressos, sendo responsável pela formação de várias gerações assim como pela propagação de uma vertente da história nacional brasileira.

Apesar de autor de uma das mais conhecidas coleções a respeito da história do Brasil denominada História do Brasil em dez volumes capitaneada pela editora carioca J. Saraiva, José Francisco da Rocha Pombo ou simplesmente Rocha Pombo é, hoje um intelectual pouco conhecido. Nascido em 1857, em Morretes, Paraná, Rocha Pombo passou os primeiros quarenta anos da sua vida (faleceu aos 86 anos de idade) em terras paranaenses procurando se inserir nos circuitos culturais da cidade. Alguns anos mais tarde, almejando uma posição mais destacada no campo intelectual ${ }^{5}$, transferiu-se juntamente com os seus familiares para a capital federal em 1897. Três anos mais tarde por ocasião das comemorações do Quarto

${ }^{5} \mathrm{~A}$ análise teórica de Pierre Bourdieu propõe a noção de campo, entendido como um espaço social de lutas configurado por agentes e instituições que congregam e que definem ao mesmo tempo as características desse mesmo campo. Pode-se afirmar a existência de um campo intelectual situado na cidade do Rio de Janeiro entre o fim do século XIX e início do século XX composto por Instituições congregadoras e consagradoras de intelectuais, tais como a Academia Brasileira de Letras (ABL), Instituto Histórico e Geográfico Brasileiro (IHGB), Colégio Pedro II e Escola Normal. Ao transferir-se para a cidade do Rio de Janeiro, Rocha Pombo procurava estar mais "perto" dos grandes centros literários do país assim como mais próximo dos intelectuais que o compunham, das suas respectivas reuniões e publicações. Para maiores detalhes sobre o conceito de campo de Bourdieu ver: BOURDIEU, Pierre. "O costureiro e sua grife: contribuição para uma teoria da magia". Educação em Revista, Belo Horizonte, nº 34, 2001. 
centenário de Descobrimento do Brasil, Rocha Pombo publicou o livro O Paraná no Centenário ${ }^{6}$, obra em que evidencia os modos culturais da comunidade paranaense. Nesse mesmo ano, Rocha Pombo, como intelectual, ingressou no Instituto Histórico e Geográfico Brasileiro, como sócio efetivo por meio da apresentação do já citado O Paraná no Centenário e do premiado Compêndio de História da América ${ }^{7}$ no concurso de 1899, narrativa em que retrata os males de origem da América Latina ${ }^{8}$. Essas duas obras indicam a

${ }^{6}$ Devido aos festejos de comemoração do Quarto Centenário do Descobrimento do Brasil, cada estado brasileiro deveria contribuir com algum escrito de sua história local. Conforme indica o prefácio escrito por Rocha Pombo que compõe a obra em questão, o Centro Paranaense sediado na cidade do Rio de Janeiro reuniu os associados a 19 de dezembro de 1899 e decidiu participar dos festejos comemorativos do descobrimento. Nesta ocasião, Rocha Pombo fora designado para a escrita de um livro referente ao Paraná estando o respectivo Centro responsabilizado pela impressão da obra. Juntamente a ajuda pecuniária de alguns paranaenses residentes no Rio de Janeiro, o Governo do Paraná acudiu a impressão do livro por intermédio de um projeto apresentado ao Congresso estadual pelo senador Vicente Machado, pouco tempo depois convertido em lei. Para maiores informações ver: ROCHA POMBO. "O fim deste livro". In: O Paraná no Centenário: 1500-1900. $2^{\mathrm{a}}$ ed. Rio de Janeiro: J. Olympio; Curitiba: Secretaria da Cultura e do Esporte do Estado do Paraná, 1980, pp. 3-5.

${ }^{7}$ Para maiores detalhes ver: SANTOS, Ivan Norberto dos. A historiografia amadora de Rocha Pombo: embates e tensões na produção historiográfica brasileira da Primeira República. Rio de Janeiro: UFRJ/IFCS/PPGHIS, 2009.

${ }^{8}$ Há uma influência direta da perspectiva de Rocha Pombo a respeito da América Latina sobre o projeto de Manuel Bomfim (1868-1932) então relator da Instrução Pública do Rio de Janeiro. Para os autores, os males atuais da América Latina são 
iniciativa de Rocha Pombo em se inserir no campo intelectual da Primeira República por meio do partilhamento de um habitus ${ }^{9}$ tipicamente intelectual condicionando os modelos de escrita e direcionando as ações a fim de possibilitar o ingresso em Instituições configuradoras desse espaço social.

Durante a sua estada na cidade do Rio de Janeiro, Rocha Pombo escreveu e publicou diversos livros, artigos e poemas. Uma dessas obras foi Nossa Patria lançada em 1917 pela Editora Melhoramentos, livro que teve inúmeras reedições, como já citado. Além das obras, Rocha Pombo atuou como professor, jornalista, romancista e historiador. Incorporou-se ao grupo literário ${ }^{10}$ dos simbolistas originários do Paraná do qual um dos membros era Nestor Victor ${ }^{11}$, um dos principais contatos de amizade de Rocha

oriundos do passado "funesto" de certo parasitismo das metrópoles. Para maiores detalhes ver: MARTINS, Wilson. História da inteligência brasileira. Vol. V. São Paulo: Editora Cultrix, 1978, [p. 274].

9 BOURDIEU, Pierre. "Por uma ciência das obras". In: Razões práticas: sobre a teoria da ação. Campinas: São Paulo: Papirus, 1996, pp. 53-91.

${ }^{10}$ Para maiores detalhes ver: A Chronica: Semanario Illustrado de litteratura e arte. Rio de Janeiro, 1899 - vol. 1. Disponível para consulta no Instituto Histórico e Geográfico Brasileiro (IHGB).

11 A amizade entre Rocha Pombo e Nestor Victor foi definidora para a transferência do paranaense para a capital federal em 1897. De acordo com um depoimento escrito por Viariato Correa também pertencente ao círculo de amizades de Rocha Pombo, Nestor Victor a ajuda financeira de Nestor Victor foi crucial para a transferência e permanência de Rocha Pombo e de seus familiares na 
Pombo e personagem fundamental na mediação entre o universo intelectual e o paranaense. Retomando a escrita, Rocha Pombo escreveu para a imprensa carioca uma série de artigos favoráveis à instrução pública e em defesa das classes operárias e de suas manifestações. Fez parte da Universidade do Povo, instituição fundada por Elísio de Carvalho "para empreender a instrução superior e a educação social do proletariado", onde atuava como professor de História Geral.

Com a finalidade de oferecer uma interpretação da realidade nacional, Rocha Pombo começou a publicar a sua coleção História do Brasil (1905) em dez volumes, concluída em 1917 como já mencionada. Fortemente atacada pela crítica da época, principalmente por Capistrano de Abreu, que como membro da comissão avaliadora, reprovou Rocha Pombo como candidato a uma cátedra de História no Colégio Pedro II. Segundo Capistrano, a História do Brasil de Rocha Pombo era mais uma compilação de outros tantos estudos científicos falhos que pouco continham de pesquisa documental. Alguns anos mais tarde, Rodolfo Garcia ${ }^{12}$, sucessor de Capistrano de Abreu, ao tomar posse na Academia Brasileira de Letras em 1936 se referia à Rocha Pombo como um historiador impossibilitado de recorrer aos arquivos europeus pela escassez de tempo, ficando assim restrita a elaboração de sua História

cidade do Rio de Janeiro. Para maiores detalhes ver: CORREA, Viriato. "Rocha Pombo”. Jornal do Brasil, Rio de Janeiro, 28 de junho de 1933.

${ }^{12}$ Para maiores detalhes ver: Revista da Academia Brasileira de Letras, vol. 48. 
do Brasil ao aproveitamento do que os outros escritores já haviam preparado.

Alguns anos mais tarde em 1933 após duas outras tentativas frustradas, Rocha Pombo conseguiu ingressar na Academia Brasileira de Letras ocupando a vaga de Alberto Faria na cadeira de $\mathrm{n}^{\circ} 39$. Assumiu a vaga de maneira informal devido ao seu agravado estado de saúde. Dias mais tarde a 26 de Junho do mesmo ano faleceu em sua casa na cidade do Rio de Janeiro. De modo geral, a maior parte de sua vida profissional foi dedicada à produção de livros escolares que tinham por objetivo promover a divulgação da História ao público infanto-juvenil e aos professores em formação. Mais do que o direcionamento de uma escrita para os pequenos leitores ou para a pesquisa na área de História do Brasil, a trajetória ${ }^{13}$ que procurou inserir-se nos meios e instituições intelectuais do período em questão. As posições sucessivamente ocupadas nos diferentes estados do campo intelectual republicano elucidam tal prerrogativa assim como as tentativas ora frustradas ou não, as negativas, as investidas, todas as características de um habitus particular e de um compartilhamento das artes de um "jogar" tipicamente intelectual.

\footnotetext{
${ }^{13}$ Para maiores detalhes ver: BOURDIEU, Pierre. "Por uma ciência das obras", pp. 53-91. No caso em questão é possível identificar essas sucessivas posições através da análise da atuação de Rocha Pombo no Instituto Histórico e Geográfico Brasileiro (IHGB). Ingressante na data de 3 de Agosto de 1900 na instituição como sócio efetivo, a 21 de Agosto de 1921 foi possível localizar uma tentativa de ascensão como sócio honorário levando em consideração os serviços prestados ao IHGB.
} 


\section{Criando o sentimento de nacionalidade}

A mudança da conjuntura político brasileira em fins do século XIX e início do século XX com a emergência da República acarretou exigências de caráter nacionalista como a formação de uma população cada vez mais identificada com aspectos próprios de uma cultura que se construía como brasileira e que ao mesmo passo definia caracterizava o que de fato era o Brasil. Conforme a historiadora Ângela de Castro Gomes, havia a necessidade de sustentar o vínculo efetivo que uma espécie de uma pedagogia da nacionalidade estabelecia com a construção de uma cultura política republicana que precisava ser produzida no período do fim do século XIX e da primeira metade do século XX. ${ }^{14}$ Esse momento foi determinante para a construção de "um passado histórico nacional", que seria edificado, difundido e elaborado por um conjunto de intelectuais. Mais do que afirmar a existência de uma conjuntura propícia para o estabelecimento de uma história genuinamente brasileira com o surgimento de Institutos Históricos incumbidos de talhar nas páginas da História os nossos "principais" acontecimentos, a problemática que surge é: qual a necessidade tácita que motiva o estabelecimento de uma história? O que e de que maneira fixa as regras e determina as maneiras de agir ou as formas certas de escrever essa história, no nosso caso a História brasileira? Não seria

\footnotetext{
${ }^{14}$ GOMES, Ângela de Castro. "República, educação e história pátria no Brasil e em Portugal".
} 
mais adequado inverter a pergunta inicial e propor o seguinte questionamento: Não foram os Institutos Históricos que construíram o Estado Nação, mas a Nação que conjugava os Institutos Históricos? Poderíamos pensar em termos da existência de certa mobilidade cultural de determinadas épocas e sociedades que engendram determinadas práticas para começar a responder tais questionamentos. É possível afirmar que há a existência de certa mobilidade cultural, nesse caso traduzida na constituição dos Institutos Históricos, que garante a sobrevivência de tais programas nacionais da mesma forma que são efetivos na manutenção das próprias culturas ${ }^{15}$. O estabelecimento de divisões na história da escrita da história ${ }^{16}$ entre os séculos XVIII e XX traduzidas em momentos significativos como: o arcadismo, o romantismo e o cientificismo elucidam as características mais particulares de cada um desses movimentos em consonância com as modificações de produção do discurso histórico. O século XIX, na realidade, trouxe a modificação na própria relação entre o sujeito e objeto e o papel das fontes na elaboração do conhecimento histórico ${ }^{17}$. Entretanto não há

15 GREENBLAT, Stephen. "Cultural Mobility: an introduction". In: Cultural Mobility: A Manifesto. Cambridge University Press, 2009, pp. 1-23.

${ }^{16}$ FALCON, Francisco José Calazans. "Capistrano de Abreu e a historiografia cientificista: entre o positivismo e o historicismo". In: NEVES, Lucia Maria Bastos Pereira das; et alli. Estudos de historiografia brasileira. Rio de Janeiro: Editora FGV, 2011, pp. 151-161.

${ }^{17}$ Idem. 
como afirmar a existência de rupturas bruscas entre um período e outro da historiografia que hoje é classificada como arcaica, romântica ou cientificista. Indubitavelmente há permanências e ressonâncias desse e de outros momentos na história e na escrita dos nossos primeiros historiadores.

No caso em questão, Nossa Pátria: Narração dos factos da História do Brasil, através da sua evolução com muitas gravuras explicativas, escrito por Rocha Pombo tece ao longo de suas páginas a História do Brasil desde o descobrimento até os anos iniciais do governo republicano. Oriunda de um período que supervalorizava o “sentimento nacional" e que nas palavras do crítico José Veríssimo era fundamental para manter o país coeso perante as outras nações do mundo que "já teriam compreendido que o sentimento nacional e conseguintemente o patriotismo", Nossa Pátria ilustra o exemplo de ressonância ${ }^{18}$ na Primeira República. Uma pequena descrição da obra pode elucidar algumas características definidoras desses traços ressonantes. Fruto desse ambiente, a Weiszflog e Irmãos, futura Companhia Melhoramentos de São Paulo, iniciou uma série de manuais dedicados ao público infanto-juvenil, algo que já fazia desde 1912 quando imprimia os compêndios da Francisco Alves, principal editora do país nesse ramo. No ano de 1916, a editora começou as suas próprias publicações encomendando a Rocha Pombo a redação

\footnotetext{
18 Para maiores detalhes ver: GREENBLATT, Stephen. "O Novo Historicismo: ressonância e encantamento”. Estudos Históricos, Rio de Janeiro, vol. 4, n. 8, 1991, p. 244-261.
} 
de um compêndio de História do Brasil direcionado para as classes dos cursos primários. No ano seguinte, Nossa Patria é lançado. Sucesso entre o grande público e entre o meio docente ${ }^{19}$, este manual representava um tipo novo de compêndio contrapondo um grande número de publicações enfadonhas e que fariam "ferrar no somno logo aos primeiros períodos". ${ }^{20}$

A capa de Nossa Patria apresenta uma gravura de duas crianças segurando a bandeira do Brasil, sendo que uma delas beija o próprio símbolo. O primeiro capítulo traz a seguinte definição acerca de pátria:

terra de nossos pais; onde viveram nossos avós; onde temos todas as recordações da nossa vida e da nossa família; onde tudo nos fala á alma - campos e mares, florestas e montanhas - e onde parece que até as estrellas e os proprios ares nos alegram mais que os outros céus! É por isso mesmo que amamos a nossa Patria mais que as outras pátrias. Nella estamos confiantes como o marujo na enseada conhecida, longe do mar alto e livre das tormentas. Ella é para nós como a nossa propria Mãi; pois nos abre o seu seio e nos protege, como si fosse uma continuação dos nossos lares. ${ }^{21}$

\footnotetext{
${ }^{19}$ DONATO. Hermâni. 100 anos da Melhoramentos. São Paulo: Melhoramentos, 1990.

${ }^{20}$ ORIÁ, Ricardo. “A Companhia Editora Nacional e a Literatura Escolar”. In: O Brasil contado às crianças: Viriato Corrêa e a literatura escolar brasileira (19341961). São Paulo: Annablume, 2011, pp. 83-116.

${ }^{21}$ ROCHA POMBO, Nossa Patria, p. 5.
} 
Como é possível perceber já nessa primeira definição, o caráter do livro era o de narrar a história brasileira estimulando nos estudantes, crianças ou adultos, o sentimento de afeição ao território brasileiro. No decorrer dos capítulos, o paranaense destaca os aspectos aos simbolismos nacionais como a bandeira, os fatos que marcaram a história brasileira tais como a independência $e$ posteriormente vai destrinchando o período do descobrimento e da formação colonial. Nas palavras de Circe Bittencourt ${ }^{22}$, o grande diferencial de Nossa Patria é a inclusão de temas e histórias do cotidiano das crianças e também a exposição de dados do mundo do trabalho, representando os agentes desse mundo social.

Além disso, outra característica "inovadora" de Nossa Patria e fonte de exemplificação de certa ressonância desse momento se traduzem na composição elaborada por Rocha Pombo da matriz brasileira. Conforme o explicitado pelo autor, o povo brasileiro constituía-se de três raças: índios, negros e brancos (portugueses), comum aos historiadores da Primeira República. A metodologia adotada por Rocha Pombo ressalta nos capítulos "Os índios", "Os africanos" e os "Os europeus" as principais características dessas três "raças" numa ótica positivada e harmoniosa da miscigenação. Essa perspectiva empreendida pelo autor antecipou uma teoria

\footnotetext{
${ }^{22}$ BITTENCOURT, Circe. Pátria Civilização e Trabalho: o ensino de história nas escolas paulistas (1917-1939). São Paulo: Dissertação de Mestrado apresentada à Faculdade de Filosofia, Letras e Ciências Humanas da Universidade de São Paulo, 1988.
} 
posteriormente difundida ao longo dos anos 1930 ao mesmo passo que refletia a necessidade de conformar uma imagem da população brasileira uniforme. Segundo o autor, os índios:

Dissemos que Martim Affonso começou a povoar o Brasil; mas é preciso explicar que começou a povoal-o de portuguezes, pois estes já encontraram aqui populações de outra raça. Eram os índios. Estes ainda estavam muito atrazados quanto á civilização. Viviam em grupos de famílias (tribus), mudando sempre de um lugar para o outro, fazendo longas paradas, mais ou menos longas, á margem dos grandes rios, ou perto das bahias. ${ }^{23}$

Além dos índios, os africanos eram:

Esta gente era tambem selvagem como os indios, e vivia lá quasi como os indios vivam aqui. Apenas os africanos não eram livres como os indios; tinham os seus reis, chamados sobas, que com eles eram muitos crueis. Aquelles reis vendiam gente como si fosse gado. Sabendo disso, os nossos colonos mandavam lá comprar quantos queriam para os ajudarem nas plantações. O africano é preto por causa do clima da Africa, que é muito quente; mas é uma raça muito boa, principalmente de muito bom coração. ${ }^{24}$

E os portugueses,

${ }^{23}$ ROCHA POMBO, Nossa Patria, p. 26.

${ }^{24}$ Idem, p. 32. 
Quando Martim Affonso chegou á ilha de S. Vicente, já encontrou ali alguns portuguezes, entre os quaes um, chamado João Ramalho, que se dera muito bem com os indios, e que vivia muito respeitado entre elles desde muitos annos. Cásara com uma índia de nome Bartira, filha de um chefe; e deixou grande descendencia. (...) Mas, a vinda de europeus para o Brasil augmentou muito, depois que Martim Affonso fundou a primeira villa. Não se demorou que muitos outros pontos da costa fossem povoados". ${ }^{25}$

E conclui acerca da população brasileira,

Vê-se, portanto, que a população do Brasil se formou dessas tres raças que temos indicado: os indios, que já estavam aqui; os africanos, que vieram como escravos; e os europeus, que tomaram conta do paiz. Por isso, o brasileiro tem as qualidades mais notaveis dessas tres raças: - é altivo, amoroso e intelligente. $^{26}$

Conforme indicam estudiosos ${ }^{27}$ da temática racial, as primeiras décadas do século XX tinham sido impregnadas de certa visão pessimista garantindo a sociedade brasileira uma perspectiva

\footnotetext{
${ }^{25}$ Idem, p. 33-35.

${ }^{26}$ Idem, p. 35.

${ }^{27}$ LACOWICZ FILHO, Estanislau; LAVERDI, Robson. "Raça e racismo na sala de aula: notas sobre o debate do "racismo a brasileira" (dos anos 1930 aos nossos dias)". Disponível

em:

http://www.diaadiaeducacao.pr.gov.br/portals/pde/arquivos/501-4.pdf, acesso em 19/08/2013.
} 
negativada de sua história podendo ser identificada nas narrativas de Afrânio Peixoto, Olavo Bilac, Coelho Neto, João Ribeiro entre outros. $\mathrm{Na}$ contracorrente dessa teoria, Rocha Pombo procurava promover a exaltação da História brasileira por meio da valorização das três vertentes sociais que compuseram a nossa sociedade, asserção esta que anos mais tarde se cristalizaria nos escritos de Gilberto Freyre. De acordo com os teóricos no assunto:

Nos anos 1930, uma nova visão, tida como oficial foi construída. A hibridização - agora menos biológica e mais cultural - é destacada, não mais como veneno, como algo que iria deturpar o elemento novo criado, mas é vista como salvadora ou redentora. E, com isso, autores como Gilberto Freyre e Donald Pierson, "ligados" á política do Estado Novo, definem o país pela sua singularidade racial, transformada em "solução". ${ }^{28}$

Para além das questões raciais e persistindo na exposição de uma narrativa promotora da exaltação patriótica, Rocha Pombo insere em seu texto a descrição da organização governamental e da formação de cidades e vilas na colônia conjuntamente a formação de um sentimento de "brasilidade". Novamente nesse capítulo é disposta a gravura de crianças admirando a bandeira do Brasil. Avançando um pouco mais pelas páginas de Nossa Patria e atingindo o momento em que aborda a Proclamação da República, o autor aponta que a principal causa da Proclamação da República era o agravado estado

\footnotetext{
${ }^{28}$ Idem, p. 6.
} 
de saúde do imperador Pedro II e o surgimento de uma possível insatisfação popular em ter no governo a Princesa Isabel. Dada essas condições, os militares segundo Rocha Pombo, assumiram o papel de fazer nascer à República, convocando os Estados e o congresso constituinte. Na última página de sua obra, Rocha Pombo encerra a narrativa retomando a necessidade de que o povo brasileiro desenvolvesse o sentimento patriótico, pois o que seria

muito grato aos nossos corações é sentir como é bella a nossa historia; como tem lances que nos commovem, e que mostram quanto é nobre a funcção que, com o concurso de outras tantas, a nossa raça vai ter na América. ${ }^{29}$

Inegavelmente considerada o maior sucesso de Rocha Pombo, Nossa Patria teve uma longa vida editorial, sendo reeditada mais de oitenta vezes e tendo um número de exemplares que extrapolava a casa numérica dos 450.000. Graças à penetração da editora em vários estados brasileiros como já citado, Nossa Patria foi recomendada em inúmeros colégios brasileiros para a Instrução Pública. No entanto, no decorrer dos anos este sucesso sofreu algumas importantes modificações revelando a existência de certa instabilidade textual no universo dos livros. Mudanças a cada edição, introdução em diversos estados e escolas, alterações no texto, na grafia e introdução de imagens. Todas essas características elucidam a importância em se

${ }^{29}$ ROCHA POMBO, Nossa Patria, p. 154. 
analisar os paratextos editoriais assim como evidenciar a sociologia dos textos. Nas palavras de Chartier,

O processo de publicação, seja lá qual for sua modalidade, é sempre um processo coletivo que requer numerosos atores e não separa a materialidade do texto da textualidade do livro. Desse modo, é inútil querer distinguir a substância essencial da obra, tida como sempre semelhante a si mesma, e as variações acidentais do texto, consideradas irrelevantes para a sua significação. ${ }^{30}$

No que concerne a Nossa Patria, o livrinho fora feito para "as crianças e homens simples do povo". Nas palavras de Rocha Pombo,

Este livrinho é feito para a intelligencia das crianças e dos homens simples do povo. Nestes dias, que alvorecem tão novos, em que se procura crear o culto da patria, penso que o primeiro trabalho para isso é fazer a patria conhecida daquelles que a devem amar. Não se ama uma terra sinão quando alguma coisa sagrada a ella nos prende - algum sacrificio, ou alguma tradição gloriosa. São essas coisas que firmam a nossa existencia moral. Sentir o que fizeram de grande os nossos antepassados equivale a tomar o compromisso de os continuar na história. Os nossos annaes, comquanto sejamos novos no mundo, registram lances de que nos podemos orgulhar. Fixal-os, em suas linhas geraes, na

\footnotetext{
${ }^{30}$ CHARTIER, Roger. "Mistério estético e materialidades da escrita”. In: Inscrever e apagar: Cultura escrita e literatura (séculos XI-XVIII). São Paulo, Editora Unesp, 2007, p. 13.
} 
alma das gerações, é, pois, o processo mais pratico e seguro de nella crear e nutrir o sentimento da patria. É o que procuro aqui fazer com todo carinho. Outros poderão fazer coisa melhor, com mais talento; mais eu escrevi este livrinho com todo o meu coração. ${ }^{31}$

Além de dedicar-se às camadas mais simples da população o suporte em Nossa Patria fora montado numa versão pequena, com texto objetivo, conciso e com gravuras ilustrativas indicam a materialidade das obras e de que forma estas influenciam na propagação dos livros e na leitura do público alvo que se apropria, inventa e produz significados dos mais diversos. Segundo Chartier,

A leitura é sempre apropriação, invenção, produção de significados. Segundo a bela imagem de Michel de Certeau, o leitor é um caçador que percorreu terras alheias. Apreendido pela leitura, o texto não tem de modo algum - ou ao menos totalmente - o sentido que lhe atribui seu autor, seu editor ou seus comentadores. Toda história da leitura supõe, em seu princípio, esta liberdade do leitor que desloca e subverte aquilo que o livro lhe pretende impor. Mas esta liberdade leitora não é jamais absoluta. Ela é cercada por limitações derivadas das capacidades, convenções e hábitos que caracterizam, em suas diferenças, as práticas de leitura. Os gestos mudam segundo os tempos e lugares, os objetos lidos e as razões de ler. Novas atitudes são inventadas, outras se extinguem. Do rolo antigo ao códex medieval, do livro

${ }^{31}$ ROCHA POMBO. Nossa Pátria, p. 3. 
impresso ao texto eletrônico, várias rupturas maiores dividem a longa história das maneiras de ler. Elas colocam em jogo a relação entre o corpo e o livro, os possíveis usos da escrita e as categorias intelectuais que asseguram sua compreensão. ${ }^{32}$

Nesse ínterim particular do universo da leitura e de suas maneiras de permitir a leitura, Nossa Patria se insere. Dentre as inúmeras reedições que contabilizam o número de 88 , podem-se citar notáveis modificações. De acordo com Lucchesi,

A $18^{\mathrm{a}}$ edição do livrinho, de 1923, traz a seguinte informação "Approvada officialmente nos Estados de S. Paulo, Santa Catharina, Sergipe, Maranhão, e adoptada no ensino desses estados e dos Paraná, Bahia e Rio Grande do Norte”. Na 62a, publicada no final de 1920, o escopo do livro amplia-se passando a ser "Adoptado em todos os estados do Brasil." (...) Até pelo menos a $79^{\mathrm{a}}$ edição, tanto o texto como as gravuras explicativas sofreram apenas algumas correções pontuais. A linguagem foi atualiza, a antiga moldura oval, que enquadrava as figuras de "personagens ilustres", substituída pela moldura retangular, e a matéria referente ao período republicano foi sendo, progressivamente, aumentada. Apenas em 1949, na 83a edição, o texto sofreria uma correção maior, com a retirada de

\footnotetext{
${ }^{32}$ CHARTIER, Roger. "O leitor - entre limitações e liberdade". In: A aventura do livro: do leitor ao navegador. São Paulo: Editora UNESP; Imprensa Oficial do Estado de São Paulo, 1999, p. 77.
} 
trechos sobre a Guerra do Paraguai considerados, então, ofensivos à nação paraguaia. ${ }^{33}$

Como exposto acima, as modificações podem ser percebidas a cada edição. A obra trabalhada na elaboração desse artigo corresponde a $34^{\mathrm{a}}$ edição e também podem ser identificadas a partir dos seguintes trechos:

\begin{abstract}
"Approvada officialmente nos estados de S. Paulo, Santa Catharina, Sergipe, Maranhão e adoptada no ensino desses estados e dos de Paraná, Bahia e Rio Grande do Norte."

“Autorizo a Companhia Melhoramentos de São Paulo a usar na composição dos compêndios que para ella tenho escripto, e estou escrevendo, a graphia que lhe convier.
\end{abstract}

Rio - Março 1925

Rocha Pombo.”

Ao analisar essas diferenças, é possível atribuir às obras a sua materialidade e traçar o processo de produção que resultou nas mesmas. Um livro acabado, pronto representa uma versão doutrinária apresentada pelo editor e pelo revisor. É alma do livro ${ }^{34}$. Uma obra não é confeccionada somente pelo autor, mas recebe a

${ }^{33}$ LUCCHESI, F. . "Criando a Nação: os livros didáticos de história do Brasil de Rocha Pombo (1857-1933)”. Educação on-Line (PUCRJ), v. 3, p. 5, 2008, p. 3.

${ }^{34}$ CHARTIER, Roger. “A prensa e as fontes - Dom Quixote na oficina de impressão”. In: Inscrever e apagar, p. 95. 
forma de todos aqueles atuam na sua elaboração. Editores, revisores, tradutores, tipógrafos entre outros são importantes peças na confecção desses objetos mágicos. Nas palavras de Chartier,

Se o corpo do livro é o resultado do trabalho dos impressores, sua alma não é confeccionada apenas pelo autor, mas recebe sua forma de todos aqueles, como o mestre impressor, os compositores e os revisores que cuidam da pontuação, da ortografia e da mise en page (paginação). Assim, Paredes recusa toda separação, antecipadamente, entre a substância essencial da obra, sempre considerada idêntica a ela mesma, independentemente de sua forma, e as variações acidentais do texto, que resultam do trabalho na oficina de impressão e não teriam, então, importância para a significação da obra. ${ }^{35}$

O fato explicitado pela citação acima pode ser visto na edição de 1925 da obra Nossa Patria em que o autor autoriza o corpo editorial a alterar a ortografia do texto, prática esta que influenciaria inclusive as formas de compreensão dos leitores. A ideia de um texto puro é inconcebível. Realizar edições de uma obra não é reencontrar um ideal, mas identificar uma preferência ou outros estados do texto, assim como as escolhas feitas quando na forma de apresentação das obras: as divisões, as pontuações, a grafia adotada e a ortografia. Os paratextos editorais revelam a história de cada edição, suas razões, implicações, escolhas, sua difusão, seus autores, leitores e etc. A partir disso é preciso considerar,

${ }^{35}$ Idem, ibidem. 
Todos os estados do texto, mesmo os mais inconscientes e bizarros, precisam ser compreendidos e, eventualmente, editados, pois, resultando tanto de gestos de escrita como de práticas da oficina, eles constituem a obra tal como foi transmitida a seus leitores. Essa existe apenas sob as formas materiais, simultâneas ou sucessivas, que lhes dão existência". ${ }^{36}$

Retomando as análises para Nossa Patria, Lucchesi aponta que,

Em 1964, 47 anos após a primeira edição de Nossa Patria, o educador Lourenço Filho fez algumas outras emendas para aquela que seria a $84^{\mathrm{a}}$ edição do livro. Em parecer explicando suas modificações, Lourenço Filho afirma ter procurado "nada alterar do pensamento do A. ou do espírito da obra", que continuava "ser perfeito, dado os fins que teve em vista": difundir a história nacional nas classes primárias, visando inculcar nas crianças o "amor" à pátria. ${ }^{37}$

Novamente a asserção acerca da instabilidade do texto se comprova. $\mathrm{O}$ tradutor, assim como o parecerista, atua diretamente na composição e na recepção das obras. O caso de Lourenço Filho ilustra bastante esse exemplo, ao influenciar na difusão da história nacional nas classes primárias alterando a narrativa do autor. Essa ocorrência caracteriza o mundo intelectual e dos livros não se

\footnotetext{
${ }^{36}$ Idem, p. 98.

${ }^{37}$ LUCCHESI, “Criando a Nação”, p. 3.
} 
dissocia do político estando diretamente ligado a processos de transmissão cultural, com patrimônios dos seus antecessores e também a um conjunto de redes de sociabilidade diversas como as verificadas nas relações entre as editoras e os próprios governadores. Espaços sociais como salões, cafés, academias, editoras, cartas, revistas, escolas são meios de tessituras de redes de sociabilidade ao mesmo passo em que são locais para a análise de fermentação e circulação de ideias $^{38}$. Uma análise dos paratextos editoriais e da conjuntura de interesses que possibilitaram o relançamento da obra indicam de que maneira a promoção de um projeto memorialístico da história nacional esteve diretamente interligado aos trâmites editoriais, configurando uma rede de sociabilidade tipicamente intelectual.

De modo geral, o propósito dessa pesquisa foi o de evidenciar a existência de uma prática de escrita histórica nacionalista corrente entre os anos iniciais da República brasileira por meio da análise da obra Nossa Patria de Rocha Pombo. Como afirmado anteriormente, a conjuntura histórica e política do Brasil foi decisiva para promoção dessa escrita assim como para o estabelecimento dos intelectuais/escritores tais como Rocha Pombo, envolvidos com a disseminação de um sentimento de nacionalidade propriamente brasileiro, indicando que a partir desse momento o Brasil começaria a ser chamado efetivamente de nosso.

\footnotetext{
${ }^{38}$ GOMES, Ângela de Castro. "Essa gente do Rio... os intelectuais cariocas e o modernismo". Estudos Históricos, Rio de Janeiro, vol. 6, n. 11, 1993, p. 62-77.
} 
O caso de Nossa Patria é ilustrativo da materialidade dos textos e da instabilidade textual. Influências dos diretores de Instrução Pública, dos redatores, editores contribuíram na forma como os leitores receberam o texto. A capa e a obra repleta de gravuras interferiram nos modos de recepção por parte dos leitores. Os suportes, as imagens e a narrativa simplificada foram definidores do sucesso do livro e possivelmente fortaleceram as relações entre Rocha Pombo e a Editora Melhoramentos de São Paulo, resultando na encomenda de cinco compêndios por parte dessa última ao intelectual das obras: História do Brasil (para o ensino secundário): com muitos mappas históricos e gravuras explicativas, 1918, Historia de São Paulo (resumo didático), 1919, Historia do Brasil (curso superior), 1926; Historia do Paraná (resumo didático), 1930 e História Universal, 1930.

De extrema importância para a consolidação do recém implantando regime republicano, a difusão dos manuais didáticos ao longo das primeiras décadas do século $\mathrm{XX}$ refletem muito das inquietações pertinentes ao universo da cultura escrita. O temor da "perda" 39 de escritos tão caros a Nação em formação, livros como Nossa Patria foram muito valorizados. Rocha Pombo, João Ribeiro, Viriato Corrêa e tantos outros se tornaram prestigiados nos tempos da efervescência de uma escrita que se denominava patriótica. $O$ caso de Nossa Patria além de exemplificar esse momento, ilustra a

\footnotetext{
${ }^{39}$ CHARTIER, Roger. A aventura do livro: do leitor ao navegador.
} 
trajetória das obras, suas histórias e as instabilidades textuais de cada edição.

\section{Fontes}

A Chronica: Semanario Illustrado de litteratura e arte. Rio de Janeiro, 1899 - vol.1. Disponível para consulta no Instituto Histórico e Geográfico Brasileiro (IHGB);

CORREA, Viriato. "Rocha Pombo". Jornal do Brasil, Rio de Janeiro, 28 de junho de 1933;

Revista da Academia Brasileira de Letras, vol. 48.

ROCHA POMBO, José Francisco da. O Paraná no centenário: 15001900. $1^{\text {a }}$ ed. Rio de Janeiro, Typographia Leuzinger, 1900.

O Paraná no centenário: 1500-1900. 2a ed. Rio de Janeiro: J. Olympio; Curitiba: Secretaria da Cultura e do Esporte do Estado do Paraná, 1980;

- Nossa Pátria : Narração dos factos da Historia do Brasil, atraves da sua evolução com muitas gravuras explicativas. 34a ed. São Paulo, Companhia Melhoramentos de São Paulo, 1925 [1917]. 


\section{Referências Bibliográficas}

BITTENCOURT, Circe. Pátria Civilização e Trabalho: o ensino de história nas escolas paulistas (1917-1939). São Paulo: Dissertação de Mestrado apresentada à Faculdade de Filosofia, Letras e Ciências Humanas da Universidade de São Paulo, 1988.

BORGES, Jorge Luís. "O Livro” In: Cinco visões pessoais. 4a ed., Brasília: UnB, 2002.

. Obras completas (Otras Inquisiciones).

BOURDIEU, Pierre. "O costureiro e sua grife: contribuição para uma teoria da magia”. Educação em Revista, Belo Horizonte, $n^{\circ}$ $34,2001$.

. "Por uma ciência das obras". In: Razões práticas: sobre a teoria da ação. Campinas: São Paulo: Papirus, 1996.

CHARTIER, Roger. A aventura do livro: do leitor ao navegador. São Paulo: Editora UNESP; Imprensa Oficial do Estado de São Paulo, 1999.

. Inscrever e apagar: Cultura escrita e literatura (séculos XI-XVIII). São Paulo: Editora Unesp, 2007.

DONATO. Hermâni. 100 anos da Melhoramentos. São Paulo: Melhoramentos, 1990. 
FALCON, Francisco José Calazans. "Capistrano de Abreu e a historiografia cientificista: entre o positivismo e o historicismo". In: NEVES, Lucia Maria Bastos Pereira das; et alli (orgs.). Estudos de historiografia brasileira. Rio de Janeiro: Editora FGV, 2011. pp. 151-161.

GENETTE, Gérard. Paratextos Editoriais. Cotia: Ateliê Editorial, 2009. (Artes do livro, 7)

GREENBLAT, Stephen. "Cultural Mobility: an introduction". In: Cultural Mobility: A Manifesto. Cambridge University Press, 2009, pp. 1-23.

GOMES, Ângela de Castro. "Essa gente do Rio... os intelectuais cariocas e o modernismo". Estudos Históricos, Rio de Janeiro, vol. 6, n. 11, 1993, p. 62-77.

- "República, educação e história pátria no Brasil e em Portugal". In: A República, a História e o IHGB. Belo Horizonte: Argvmentvm, 2009.

HALLEWELL, Laurence. O livro no Brasil: sua história. São Paulo: EdUSP, 2005, p. 468.

LACOWICZ FILHO, Estanislau; LAVERDI, Robson. "Raça e racismo na sala de aula: notas sobre o debate do "racismo a brasileira" (dos anos 1930 aos nossos dias)”. Disponível em: http://www.diaadiaeducacao.pr.gov.br/portals/pde/arquivos/501-4.pdf, acesso em 19/08/2013. 
LUCCHESI, F. “ "Criando a Nação: os livros didáticos de história do Brasil de Rocha Pombo (1857-1933)". Educação on-line (PUCRJ), v. 3, p. 5, 2008.

MACEDO, A. M. C. “O Livro do Centenário (1500-1900) e o projeto de escrita da história na virada do século XX". Anais da IV Jornada de Estudos Históricos do PPGHIS, 2009, Rio de Janeiro.

MACIEL, Laura Antunes. "Imprensa, História e Memória: da unicidade do passado às outras histórias". Patrimônio e Memória, v. 5, n. 2, p. 66-89, dez./2009.

MARTINS, Wilson. História da inteligência brasileira. Vol. V. São Paulo: Editora Cultrix, 1978.

ORIÁ, Ricardo. "A Companhia Editora Nacional e a Literatura Escolar". In: $\mathrm{O}$ Brasil contado às crianças: Viriato Corrêa e a literatura escolar brasileira (1934-1961). São Paulo: Annablume, 2011, pp. 83-116.

SANTOS, Ivan Norberto dos. A historiografia amadora de Rocha Pombo: embates e tensões na produção historiográfica brasileira da Primeira República. Rio de Janeiro: UFRJ/IFCS/PPGHIS, 2009. 